\title{
Central Vietnam needs you!
}

\author{
Joseph Ng, Singapore 119077, Singapore
}

Da Nang is one of five municipalities directly under the control of the central government. It is a city of about a million inhabitants and the major educational and business hub of Central Vietnam. There are only 70 physicians who provide obstetric and gynecological care in two municipal hospitals, six district hospitals, and six private hospitals.

Public health is a priority of the central government and demonstrated in projects like the Da Nang Oncology Hospital, with which the International Gynecologic Cancer Society (IGCS) is fortunate to partner and have as a training site. The Da Nang Oncology Hospital was one of the first five pilot sites of the IGCS Oncology Global Curriculum training, initiated in July 2017. The international mentors at this site are Dr Tri Dinh from the Mayo Clinic Jacksonville, Florida, USA and Dr Joseph $\mathrm{Ng}$ from the National University Cancer Institute, Singapore (figure 1). Dr Tran Tu Quy, vice director of Da Nang Oncology Hospital, is a gynecologic oncologist and the local supervisor of the IGCS Oncology Global Curriculum program who recruited an outstanding young physician, Dr Nhu Quynh Tran Thi, to be the

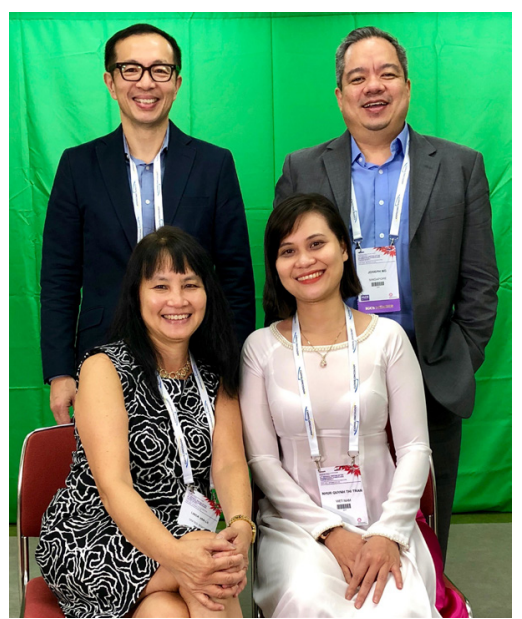

Figure 1 Dr Quynh (seated in white) with international mentors Drs Tri Dinh and Joseph $\mathrm{Ng}$ (standing left and right respectively) and program faculty member, Dr Linda van Le (seated) in Kyoto, Japan for IGCS 2018 where Dr Quynh's poster drew a lot of attention.

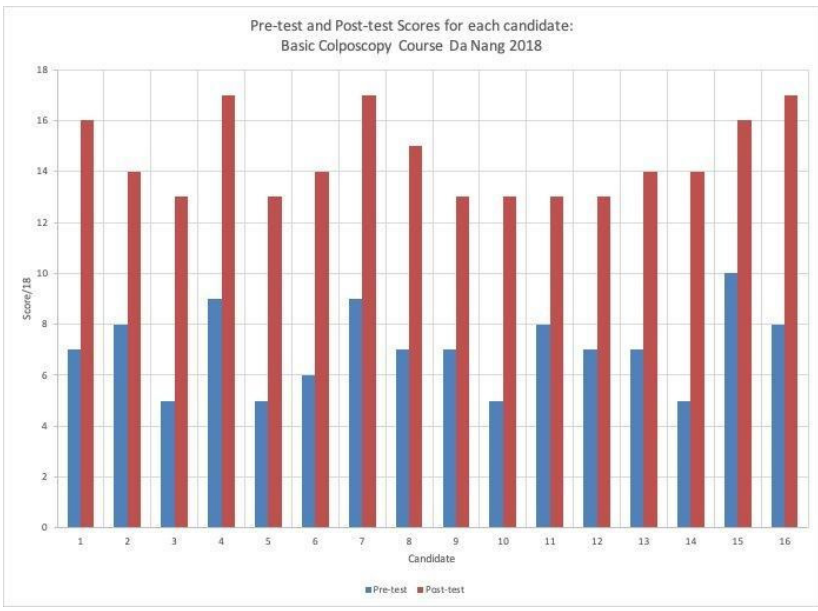

Figure 2 Test scores before (pre) and after (post) didactic teaching.

first fellow of the IGCS Global Curriculum Vietnam.

In Vietnam, the IGCS has had the unique opportunity to explore collaborative alliances in training and education. In August 2018, the IGCS and the ASCCP (formerly the American Society for Colposcopy and Cervical Pathology) conducted a joint pilot program to train primary care providers in cervical cancer prevention. Faculty members from both organizations conducted a 2-day training program in basic colposcopy and dysplasia treatment at the Center for Reproductive Health, Da Nang, with the support and endorsement of the director and vice director of the Center, Drs Tran Thao and Ngo Quang, respectively. Dr Quynh, our IGCS fellow attended, translated, and taught in the program, which included

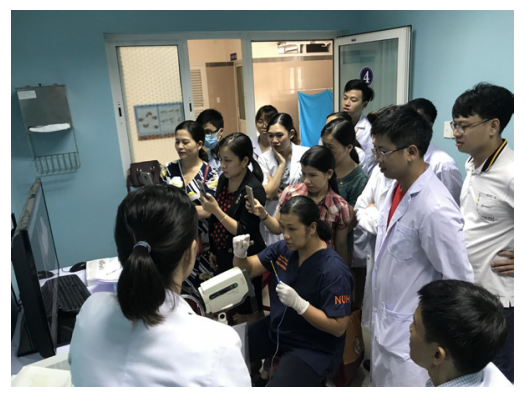

Figure 3 Dr lda Pratt of the ASCCP (seated) demonstrating a live loop electrosurgical excision procedure on a colposcopy simulator at Da Nang Oncology Hospital. didactic lectures, live demonstrations on simulators, and hands-on practical sessions. Sixteen participants, including physicians and nurses from area hospitals, participated in the program, and the feedback was unanimous that more such training programs should be conducted. The scores from pre- and post-didactic quizzes (figure 2) demonstrate the potential impact that basic didactic training can have on provider knowledge and practice. Training in basic cervical cancer prevention is needed and basic education can save the lives of women in Central Vietnam.

My involvement in Vietnam has made one thing clear to me, motivated mentors can make a difference to the lives of women in this Southeast Asian country (figure 3). Unexplored potential collaborative synergies exist between the IGCS and other global partners. The considerable aid that has been poured into Vietnam through various non-governmental organizations and professional societies, should be coordinated to raise the bar on healthcare for this country. Somewhere it is written, "the harvest is plentiful, but the workers are few." Truer words have never been spoken about the need here in Vietnam, where a little training can and will go a long way.

Correspondence to $\mathrm{Dr}$ Joseph Ng, OBGyn, Division of Gyn Onc, National University of Singapore, Singapore 119077, Singapore; joseph_ng@nuhs.edu.sg 
Contributors The corresponding author is the only author and was responsible for drafting the entire document with no significant external input from other individuals that might reasonably be attributed as authors or collaborators.

Funding The authors have not declared a specific grant for this research from any funding agency in the public, commercial or not-for-profit sectors.
Competing interests None declared.

Patient consent for publication Not required.

D Check for updates

Provenance and peer review Commissioned; internally peer reviewed.

(C) IGCS and ESG0 2019. No commercial re-use. See rights and permissions. Published by BMJ.

To cite Ng J. Int J Gynecol Cancer 2019;29:840-841.

Accepted 26 February 2019

Published Online First 3 April 2019

Int J Gynecol Cancer 2019:29:840-841.

doi:10.1136/ijgc-2019-000365 